\title{
ESTRATEGIAS DE DESCORTESÍA EN EL DISCURSO PARLAMENTARIO CHILENO
}

Impoliteness strategies in the Chilean parliamentary discourse

$147-168$

\author{
Abelardo San Martín Núñez* \\ Silvana Guerrero González**
}

\section{Resumen}

El propósito de este artículo es analizar las estrategias de descortesía verbal en una muestra de discurso parlamentario chileno. Para tal propósito se estudiaron las secuencias de discurso que manifestaban dichas estrategias en un corpus de 28 sesiones de la honorable Cámara de Diputados de Chile realizadas entre 2005 y 2007, en las que se discutieron diferentes asuntos polémicos de interés público. Para el análisis de la descortesía en el discurso político aquí realizado se consultaron los trabajos de Chilton y Schäffner (1999), Blas Arroyo (2001 y 2003) y Bolívar (2005), entre otros. Una vez analizados los textos de las transcripciones de las sesiones de la muestra se identificaron las siguientes estrategias de descortesía: atacar la imagen pública del oponente y resguardar la propia imagen pública. Asimismo, la primera de dichas estrategias se subclasificó en las siguientes tácticas: desacreditaciones, ridiculizaciones y amedrentamientos.

Palabras clave: Análisis del discurso, discurso político, descortesía, imagen.

Abstract

The purpose of this article is to analyze impoliteness strategies in a sample of Chilean parliamentary discourse. To that effect, this study puts forward an analysis of the discourse sequences manifesting these strategies in a corpus constituted by 28 sessions held between 2005 and 2007 by the honorable Chamber of Representatives of Chile, in which different and controversial issues of public interest were discussed. For the analysis of impoliteness in political discourse carried out in this study, the works of Chilton y Schäffner (1999), Blas Arroyo's (2001 and 2003) and Bolívar's (2005) were consulted, among others. Once the transcriptions of the sessions under analysis were processed, the following impoliteness strategies expressing the representatives' political goals were identified: attacking the opponent's public image and protecting the own public image. Likewise, the first of these strategies was sub-classified into the following tactics: discrediting, ridiculizing, and intimidating.

Key words: Discourse analysis, political discourse, impoliteness, face.

\section{INTRODUCCIÓN}

\subsection{Naturaleza, alcance y objetivos del estudio}

Tradicionalmente, se ha caracterizado a la interacción verbal como un medio en que los interlocutores, de modo estratégico, buscan el acuerdo y eluden el conflicto. En esta línea han surgido diferentes modelos de análisis de la cortesía verbal (Lakoff, 1973; Leech, 1983; Brown y Levinson, 1987; Haverkate, 1994, entre otros). No obstante, en 


\section{Abelardo San Martín, Silvana Guerrero}

el último tiempo se ha estudiado también la manifestación lingüística de la descortesía, es decir, de aquellos recursos verbales empleados en contextos en los que la búsqueda de desacuerdo entre los participantes se impone por sobre la búsqueda de armonía. La descortesía es una estrategia consciente, ya que los hablantes a través de los actos descorteses persiguen fines específicos muy bien definidos, mediante los cuales se pretende alterar el equilibrio interpersonal y desafiar las expectativas del oyente o las normas sociales a través de una serie de mecanismos lingüísticos (Culpeper, 1996; Kienpointner, 1997; Blas Arroyo, 2001-2003; Bolívar, 2005).

El objetivo de este estudio es analizar la forma en que se manifiesta la descortesía en un escenario especialmente conflictivo: el debate político cara a cara. Para tal fin se estudiaron los textos de las transcripciones de 28 sesiones de la honorable Cámara de Diputados de Chile realizadas entre 2005 y 2007, las que constituyen el corpus de nuestro trabajo. En dichas sesiones se discuten problemas de la contingencia nacional como el sonado fracaso en la implementación del proyecto "Transantiago", destinado a modernizar el sistema de transporte público de la capital de Chile, la malversación de recursos en organismos públicos como "Chiledeportes", la distribución de anticonceptivos de emergencia y la legislación del aborto terapéutico, entre otros temas de interés público y político.

Finalmente, es necesario precisar que si bien en el contexto de la lingüística norteamericana y en el ámbito hispánico se ha comenzado a estudiar la forma en que se manifiesta la descortesía en el discurso político, estos trabajos no han alcanzado al marco político chileno. En este sentido, esta investigación intenta ser un aporte al análisis del discurso político en Chile, sobre todo, al emplear un corpus inédito.

1.2. Breve caracterización del escenario político chileno y de la honorable Cámara de Diputados de Chile

En el ámbito de la política chilena actual existen dos grandes coaliciones que se disputan la conducción política de la nación: una de centro-izquierda, autodenominada "Concertación de Partidos por la Democracia" que gobernó el país desde marzo de 1990 hasta marzo de 2010 y otra, autodenominada "Alianza por Chile", constituida por partidos de centro-derecha y que en el periodo analizado (2005-2007) cumplió el papel de oposición. Cada una de estas coaliciones está compuesta por partidos políticos con ideas afines entre sí. La "Concertación" está conformada por el Partido Demócrata Cristiano (DC), el Partido por la Democracia (PPD), el Partido Socialista (PS) y el Partido Radical Social Demócrata (PRSD). Por su parte, la "Alianza" está integrada por Renovación Nacional (RN) y la Unión Demócrata Independiente (UDI). Por otro lado, la honorable Cámara de Diputados está integrada por 120 miembros elegidos por votación directa, en representación de los 60 distritos electorales en 
los que se encuentra dividido el país. ${ }^{1}$ El objetivo de este organismo es legislar en conjunto con el Senado y el Presidente de la República. En el trabajo de la Cámara existen dos tipos de períodos: el de sesiones ordinarias y el de sesiones extraordinarias. ${ }^{2}$ La Cámara sólo puede entrar en sesión y suscribir acuerdos con el quórum o asistencia mínima necesaria, es decir, con la concurrencia de la tercera parte de sus miembros en ejercicio.

Pese a que normalmente en las sesiones de la Cámara se genera un ambiente confrontacional, existe un Código de Conductas Parlamentarias, ${ }^{3}$ que norma el comportamiento de los diputados al interior de la Cámara. Específicamente, dicho Código señala en su Artículo 3 que los Diputados deben permanentemente observar una conducta moralmente intachable y una entrega honesta y leal al desempeño de la función y de su cargo, con preeminencia del interés general sobre el particular y, asimismo, en el Artículo $7^{\circ}$ (letras b y g) se enfatiza en que es un deber fundamental de los Diputados actuar con fraternidad frente a sus colegas, abstenerse de expresiones malévolas o injuriosas, no aludir a antecedentes personales de ellos y ser justos y respetuosos en el trato con los ciudadanos, los demás Diputados, el personal de la Corporación y, en general, con cualquier autoridad o funcionario público.

\section{MARCO CONCEPTUAL}

\subsection{El estudio de la (des)cortesía y el concepto de imagen}

La cortesía es considerada como una forma de comportamiento humano universal. Sin embargo, existe una serie de diferencias interculturales en cuanto al empleo de fórmulas corteses y su función comunicativa en cada sociedad. Fraser (1990) y Fraser y Nolen (1981) señalan que la cortesía verbal reside esencialmente en el llamado "contrato conversacional", entendiéndose por ello, los derechos y las obligaciones mutuas de las personas que llevan a cabo un intercambio.

Como es bien sabido, el concepto de imagen planteado por Goffman (1971) es un elemento central en el modelo de cortesía verbal de Brown y Levinson (1987). Tal concepto incluye dos polos: uno positivo y otro negativo. El primero corresponde a la imagen positiva que la persona tiene de sí misma, la que pretende que sea reconocida y reforzada por el resto de los miembros de la sociedad. Por su

\footnotetext{
${ }^{1}$ Artículo 47 de la Constitución Política de la República de Chile.

${ }^{2}$ En el período de sesiones ordinarias la Cámara de Diputados se ocupa del estudio, la discusión y la votación de las iniciativas que se presentan ante ella, en particular, de la aprobación, modificación o rechazo de cada proyecto de ley que le corresponda debatir. Por su parte, los períodos de sesiones extraordinarias, que se desarrollan sin fechas preestablecidas durante los recesos del Congreso, son convocados por la Comisión Permanente o a solicitud del Presidente de la República para resolver un problema específico.

${ }^{3}$ Este documento se encuentra disponible en la página Web de la Cámara de Diputados de Chile: www.camara.cl
} 


\section{Abelardo San Martín, Silvana Guerrero}

parte, la imagen negativa se refiere al deseo de cada individuo de que sus actos no sean imposibilitados por los demás. Los mismos autores identifican en los actos del lenguaje cuatro categorías de acuerdo con la imagen que es susceptible de amenazar: 1) Actos amenazadores para la imagen negativa del que los realiza, 2) Actos amenazadores para la imagen positiva del que los realiza, 3) Actos amenazadores para la imagen negativa del que los padece y 4) Actos amenazadores para la imagen positiva del que los padece. En esta investigación la imagen amenazada corresponde a aquella que se ubica en las categorías 3 y 4 . Por otro lado, Blas Arroyo (2001) señala que en la interacción social los interlocutores buscan un equilibrio, no sólo protegiendo su imagen, sino que también la de los demás. En otras palabras:

Los hablantes desarrollan estrategias de cortesía, destinadas a contrarrestar los efectos perturbadores de ciertos actos, que atacan directamente, ya sea la imagen positiva, ya sea la imagen negativa de los participantes. Las de cortesía positiva van dirigidas a preservar la imagen positiva del oyente (...) por su parte, las estrategias de cortesía negativa contrarrestan las amenazas de esos deseos de "integridad territorial" que caracterizan también cierta imagen (negativa) de los interlocutores (15).

Por otro lado, la descortesía ha sido estudiada principalmente por Lakoff (1973), Culpeper (1996), Kienpointer (1997), Martin Rojo (2000) y Haverkate (1994). Culpeper (1996) revisa las principales estrategias de descortesía utilizadas por los interlocutores, en donde el deseo de desprestigiar al oyente, disminuyendo su imagen pública, es una de las más empleadas. En esta misma línea, es fundamental el trabajo de Blas Arroyo (2001), como investigación paradigmática de los estudios recientes de descortesía en español, particularmente, de la registrada en el discurso político.

\subsection{El discurso político y el concepto de política}

Chilton y Schäffner (1999) señalan que el discurso político se interesa por relacionar las particularidades del comportamiento lingüístico con la política o con el comportamiento político. En esta investigación, el concepto de política se sustenta en lo que señalan Chilton y Schäffner (2002). De acuerdo con los autores, dicho concepto varía según la situación y los propósitos y, en general, son dos los tipos de definiciones que se pueden encontrar en la literatura:

On the one hand, politics is viewed as a struggle for power, between those who seek to assert and maintain their power and those who seek to resist [...] On the other hand, politics is viewed as cooperation, as the practices and institutions a society has for resolving clashes of interest over money, power, liberty and the like [Por un lado, la política se ve como una lucha por el poder, entre aquellos que lo buscan para asegurarlo y mantenerlo [...] Por otro lado, la política se ve como cooperación, como las prácticas y las instituciones que posee una sociedad para resolver diferencias de intereses por asuntos de dinero, poder, libertad y cosas similares (la traducción es nuestra)] (Chilton y Schäffner, 2002:5). 
En este sentido, Chilton y Schäffner (2002) apuntan a que en este concepto pueden observarse dos niveles: el micro, donde estarían las relaciones entre las personas, géneros y grupos, y el macro, donde se ubicaría el Estado como instancia que ayuda a resolver conflictos de intereses o para asegurar el dominio de poder de una persona o grupo. Asimismo, Flores e Infante (2010) plantean que la política debe ser el resultado de aceptar que existen grupos diferentes actuando de manera simultánea, en tanto que un sistema político de gobierno implica escuchar a los otros, los que pertenecen a grupos diferentes al mío. De esta forma, según las autoras, la práctica real de la política supone un permanente intercambio de ideas que (re)presentan intereses y deseos, intercambio del cual no se puede prescindir en ninguna circunstancia (538).

\subsection{El estudio de la (des)cortesía en el discurso político en español}

Como ya se indicó, el estudio de la descortesía es más o menos reciente. Bernal (2007) pone énfasis en este aspecto, señalando que: la descortesía, por su parte, se ha incorporado al campo de la investigación como objeto pleno de estudio en fechas más tardías: no es sino en la última década cuando se ha abordado con más frecuencia el problema de sus características y su definición (20).

En relación con el estudio de la (des)cortesía en el discurso político, Chilton y Schäffner (1999) señalan que las acciones que se consideren como "políticas" (lingüísticas o no) son las que involucran el poder o la resistencia. De este modo, los autores proponen cuatro funciones estratégicas: 1) coerción, 2) resistencia, oposición y protesta, 3) encubrimientos y 4) legitimación y deslegitimación. Estas estrategias se llevan a cabo por los hablantes a través de sus diferentes elecciones lingüísticas en el marco de los derechos y las obligaciones que se producen en la interacción social. Por otra parte, dichos autores afirman que estas funciones pueden observarse en un micro nivel, es decir, en las relaciones entre las personas, los géneros y los grupos, así como en un macro nivel, esto es, en el Estado como instancia que ayuda a resolver conflictos de intereses o para asegurar el dominio de poder de una persona o grupo.

De acuerdo con Bolívar (2005), en el discurso político no necesariamente se busca la armonía, sino que más bien se pretenden resaltar las diferencias y el conflicto, aunque de modo regulado, por ejemplo, mediante normas explícitas o la función de moderadores. A este respecto, Bolívar señala que:

En líneas generales, en los estudios reportados sobre el discurso político en español, cuando se habla de descortesía está bastante explícita su función estratégica y queda claro que existe un control por la búsqueda del equilibrio, que proviene de los mismos participantes en la interacción, quienes autorregulan su conducta o aceptan la participación de moderadores (Bolívar, La descortesía 146).

Por otro lado, Blas Arroyo (2001) señala que en las situaciones de comunicación política, la norma está representada, justamente, por el comportamiento descortés, puesto que los hablantes actúan deliberadamente buscando el conflicto: 


\section{Abelardo San Martín, Silvana Guerrero}

La decisión final sobre el carácter cortés o descortés de un mensaje no dependería en última instancia de su capacidad para atacar la imagen del interlocutor, sino del grado de cumplimiento de los derechos y obligaciones establecidos en ese "contrato conversacional". Si se cumple con éstos, estaríamos ante enunciados corteses, mientras que si se vulneran, nos enfrentaríamos a enunciados descorteses (Blas Arroyo, No digas chorradas 11).

La agresividad verbal en el discurso político debe estudiarse en el seno de la retórica interpersonal propuesta por Leech (1983) que da cuenta de los movimientos que efectúan los participantes de un intercambio comunicativo. Según Blas Arroyo (2001) el debate político cara a cara se convierte en una "batalla" de argumentos contrarios entre dos o más interlocutores. El arma principal de esta batalla es la agresión verbal, puesto que la victoria consiste en anular el discurso de quien está enfrente defendiendo puntos de vista diferentes. La probabilidad de que el discurso se convierta en un intercambio "pacífico" de ideas contrapuestas con recursos que puedan convencer al interlocutor se convierte en una táctica inválida en este tipo de discurso, dado que se utilizan estrategias como la ridiculización, el amedrentamiento y la invalidación de la imagen pública del adversario. ${ }^{4}$

En cuanto a las estrategias de descortesía en el discurso político, Blas Arroyo (2001) — basándose en Culpeper (1996), y su propósito de cinco estrategias de descortesía, elaboradas a partir de la división entre imagen negativa e imagen positivaplantea a su vez las siguientes estrategias y subestrategias, las que describe de modo imperativo:

1) Asocia directamente al interlocutor con intenciones o hechos negativos. Las subestrategias que propone el autor son: "Impútale fracaso o incompetencia", "Acúsale de esconder intenciones aviesas", "Réstale credibilidad" y "Acúsale de eludir su responsabilidad".

2) Dile que miente. Muchas veces esta estrategia se presenta al interlocutor por medio de un recurso intensificador que hace ver que el adversario está consciente de sus mentiras ("mientes y lo sabes"). Al tratarse de acusaciones graves, el autor señala que es frecuente que en este tipo de estrategias se utilicen atenuadores como, por ejemplo, "faltar a la verdad" o decir "medias verdades".

3) Muéstrate como despectivo frente al adversario. Las subestrategias que se desprenden de este recurso son: "Ridiculiza al interlocutor" y "No lo creía capaz de...".

4) Formula contrastes desventajosos para el interlocutor. Por medio de esta estrategia, el emisor se presenta como el polo positivo, provisto de diversas cualidades de las que carece el adversario. Generalmente, se dan a conocer

\footnotetext{
${ }^{4}$ La concepción del debate político cara a cara como una "batalla", propuesta de Blas Arroyo (2001), se sustenta, fundamentalmente, en los planteamientos de Tannen (1994, 1999), Lakoff y Johnson (1995) y Fernández (2000).
} 
errores cometidos por "el otro" (o por la coalición política a la que pertenece el adversario). A esto se refiere la primera subestrategia: "Establece comparaciones entre tu interlocutor y tú" y dentro de ésta: "Critica a personas o cosas cercanas a tu adversario".

5) Acusa al interlocutor de contradictorio. Esto se realiza mediante dos subestrategias: "Haz ver que el rival hace lo contrario de lo que dice" y "Demuestra que el rival dice cosas contradictorias" (adaptado de Blas Arroyo, 2001:19-25).

Por otro lado, la investigación de Bolívar (2005) aborda el empleo de la descortesía como estrategia en el discurso político venezolano actual. De acuerdo con dicha autora, las teorías sobre la cortesía/descortesía en su etapa incipiente han sido objeto de múltiples críticas y observaciones, puesto que las valoraciones sobre lo que es cortés, no cortés o descortés dependen del tipo de evento de habla y de la situación comunicativa analizada.

Al hablar de descortesía como estrategia política, Bolívar (2005) plantea una serie de categorías de análisis basándose en los estudios del Grupo de Análisis del discurso Político de la Universidad Central de Venezuela (Bolívar, 2002, 2005; Montero, 2003; Shiro y Núñez, 2003; Bolívar, Erlich y Chumaceiro, 2003), y en trabajos realizados por Wodak y Meyer (2003) sobre la construcción discursiva de la identidad nacional en Europa. La autora considera también los estudios de van Dijk sobre la polarización (van Dijk, 1999 y 2003), y propone que la descortesía se orienta hacia la expresión de objetivos políticos que se resumen en: a) marcar la diferencia con los oponentes, b) transformar la situación política existente y c) desmantelar/destruir el statu quo para imponer otro modelo político.

Estos tres objetivos pueden manifestarse de manera simultánea, o bien pueden desarrollarse en progresión cronológica según el grado de amenaza que producen en los interlocutores. Lo más probable es que la última meta incluya violencia física en un grado mayor. Para lograr estos objetivos políticos en el discurso se articulan las funciones estratégicas descritas por Chilton y Schäffner (1999, ver más arriba, 2.3). El cumplimiento de dichas metas se lleva a cabo mediante actos lingüísticos dicursivos y semióticos (vestimenta, movimientos, emblemas, etc.). Tomando a van Dijk (2003), Culpeper (1996), Blas Arroyo (2001) y Bolívar (1992, 1996, 2002), esta última autora postula que en el discurso político los actos discursivos se construyen para producir efectos (actos perlocutivos) que tienen distintos grados de intensidad en la amenaza de la imagen de las personas y del diálogo político democrático:

1) Descalificar: la meta política es resaltar los rasgos negativos de los oponentes en cuanto a capacidad intelectual, capacidad de liderazgo, credibilidad, coherencia, responsabilidad, cualidades personales, calidad moral, etc. 


\section{Abelardo San Martín, Silvana Guerrero}

2) Ridiculizar: el objetivo político es convertir al oponente en objeto de burla, hacer que los demás se rían de su persona, acciones o decisiones, a fin de disminuirlo como persona, como profesional o como contrincante.

3) Humillar: la meta política es degradar al oponente en su estima personal, profesional y política.

4) Amedrentar: el objetivo político es debilitar al oponente a través del miedo. Se amenaza la integridad intelectual, moral y física de las personas.

5) Ignorar: el objetivo político es no tomar en cuenta, no responder, excluir del diálogo político. El no reconocimiento del contrario entorpece y elimina la posibilidad de entendimiento democrático (adaptado de Bolívar, 2005:147-148).

Para los fines del presente estudio, es de presuponer que los actos discursivos "humillar" e "ignorar" no sean registrados en el corpus, debido a que no se aplican a la situación de interacción entre pares que caracteriza al debate entre parlamentarios, sino que es más bien pertinente en interacciones de tipo asimétrico, donde pueden aplicarse acciones de mayor fuerza o violencia en contra de los opositores políticos.

En el diseño y realización de la presente investigación hemos adaptado a la realidad política chilena los estudios de descortesía en el discurso político realizados, principalmente, por Blas Arroyo (2001) y Bolívar (2005) quienes consideran la interacción verbal como una práctica social que va moldeándose de acuerdo con las características culturales de cada comunidad.

\section{METODOLOGÍA}

\subsection{Corpus}

La muestra de discurso utilizada para nuestro análisis consta de 28 sesiones de la honorable Cámara de Diputados de Chile, las que en texto transcrito suman 2.907 páginas. Las intervenciones respectivas se produjeron entre mayo de 2005 y agosto de 2007. El acceso al corpus se encuentra disponible en el sitio electrónico de la cámara de diputados (www.camara.cl), en el que se publican diversos materiales sobre las actividades de la Cámara. En nuestra investigación utilizamos los documentos públicos y oficiales en los que se consignan los nombres de los diputados, los ministros y los funcionarios de gobierno asistentes, los temas tratados, el resultado nominal de cada votación, un sumario de los documentos de los que se haya dado cuenta y las transliteraciones de cada una de las intervenciones en las sesiones de la Cámara.

En lo que sigue, presentamos las características sociodemográficas de los diputados que participaron en las 28 sesiones analizadas. En las Tablas 1 y 2 se presenta el detalle de los diputados y ministros de gobierno cuyas intervenciones conforman la muestra de discurso en estudio. 
TABLA 1. PARTIDO POLÍTICO DE LOS PARLAMENTARIOS QUE INTERVINIERON EN LAS SESIONES DE LA CÁMARA DE DIPUTADOS CONSIDERADAS EN EL CORPUS

\begin{tabular}{|l|l|}
\hline \multicolumn{1}{|c|}{ Nombre } & \multicolumn{1}{|c|}{ Partido Político $^{\text {5 }}$} \\
\hline Accorsi, Enrique & PPD \\
\hline Aedo, René & RN \\
\hline Aguiló, Sergio & PS \\
\hline Alinco, René & PPD \\
\hline Allende, Isabel & PS \\
\hline Alvarado, Claudio & UDI \\
\hline Álvarez, Rodrigo & UDI \\
\hline Barros, Ramón & UDI \\
\hline Becker, Germán & RN \\
\hline Bobadilla, Sergio & UDI \\
\hline Burgos, Jorge & DC \\
\hline Cardemil, Alberto & IND \\
\hline Correa, Sergio & UDI \\
\hline Cristi, María Angélica & UDI \\
\hline Cubillos, Marcela & UDI \\
\hline Dittborn, Julio & UDI \\
\hline Duarte, Gonzalo & DC \\
\hline Egaña, Andrés & UDI \\
\hline Enríquez-Ominami, Marco & PS \\
\hline Errázuriz, Maximiano & RN \\
\hline Espinoza, Fidel & PS \\
\hline Forni, Marcelo & UDI \\
\hline García, René & RN \\
\hline García - Huidobro, Alejandro & UDI \\
\hline Girardi, Guido & PPD \\
\hline Ibáñez, Gonzalo & UDI \\
\hline Insunza, Jorge & PPD \\
\hline Jaramillo, Enrique & PPD \\
\hline Kast, José Antonio & UDI \\
\hline Latorre, Juan Carlos & DC \\
\hline Leal, Antonio & PPD \\
\hline Letelier, Juan Pablo & PS \\
\hline Lobos, Juan & UDI \\
\hline Longton, Alfonso & PS \\
\hline Lorenzini, Pablo & DC \\
\hline Martínez, Rosaura & RN \\
\hline Melero, Patricio & UDI \\
\hline Monckeberg, Cristián & RN \\
\hline Montes, Carlos & PS \\
\hline & \\
\hline & \\
\hline
\end{tabular}

\footnotetext{
5 Estas siglas corresponden a los siguientes nombres de partidos políticos: $\mathrm{PPD}=$ Partido por la Democracia, RN= Renovación Nacional, PS= Partido Socialista, UDI= Unión Demócrata Independiente, $\mathrm{DC}=$ Democracia Cristian, $\mathrm{IND}=$ Independiente, $\mathrm{PRSD}=$ Partido Radical Social Demócrata.
} 


\section{Abelardo San Martín, Silvana Guerrero}

\begin{tabular}{|l|l|}
\hline Moreira, Iván & UDI \\
\hline Muñoz, Adriana & PPD \\
\hline Nogueira, Claudia & UDI \\
\hline Norambuena, Iván & UDI \\
\hline Núñez, Marco Antonio & PPD \\
\hline Olivares, Carlos & DC \\
\hline Pascal, Denise & PS \\
\hline Paya, Darío & UDI \\
\hline Pérez, José & PRSD \\
\hline Rojas, Manuel & UDI \\
\hline Rubilar, Karla & RN \\
\hline Sabag, Jorge & DC \\
\hline Saffirio, Eduardo & DC \\
\hline Salaberry, Felipe & UDI \\
\hline Súnico, Raúl & PS \\
\hline Turres, Marisol & UDI \\
\hline Uriarte, Gonzalo & UDI \\
\hline Vargas, Alfonso & RN \\
\hline Verdugo, Germán & RN \\
\hline Vidal, Ximena & PPD \\
\hline
\end{tabular}

TABLA 2. MINISTROS DE GOBIERNO QUE INTERVINIERON EN LAS SESIONES DE LA CÁMARA DE DIPUTADOS CONSIDERADAS EN EL CORPUS

\begin{tabular}{|l|l|}
\hline \multicolumn{1}{|c|}{ Nombre } & \multicolumn{1}{c|}{ Ministerio } \\
\hline Zilic Hrepic, Martín & Educación \\
\hline Espejo Yaksic, Sergio & Transportes \\
\hline Velasco Barahona, Belisario & Del Interior \\
\hline Ravinet De la Fuente, Jaime & Defensa \\
\hline
\end{tabular}

\subsubsection{Sesiones que conforman el corpus}

Se seleccionaron aquellas sesiones de la Cámara de Diputados cuyas temáticas a tratar tuvieron polémica por su repercusión en la vida nacional o por el interés público suscitado en la ciudadanía.

En la Tabla 3 se especifican el número de legislatura y sesión y la fecha de las sesiones en estudio, en orden cronológico.

TABLA 3. IDENTIFICACIÓN DE LAS SESIONES DE LA HONORABLE CÁMARA DE DIPUTADOS DE CHILE QUE CONFORMAN EL CORPUS

\begin{tabular}{|l|l|l|}
\hline Número de Legislatura & Número de Sesión & Fecha (día/mes/año) \\
\hline $352^{\mathrm{a}}$ (extraordinaria) & $77^{\mathrm{a}}$ & $17 / 05 / 2005$ \\
\hline $353^{\mathrm{a}}$ & $37^{\mathrm{a}}$ & $31 / 08 / 2005$ \\
\cline { 2 - 3 } & $51^{\mathrm{a}}$ & $12 / 10 / 2005$ \\
\cline { 2 - 3 } & $66^{\mathrm{a}}$ & $10 / 01 / 2006$ \\
\cline { 2 - 3 } & $68^{\mathrm{a}}$ & $17 / 01 / 2006$ \\
\cline { 2 - 3 } & $73^{\mathrm{a}}$ & $24 / 01 / 2006$ \\
\hline \multirow{3}{*}{$354^{\mathrm{a}}$} & $5^{\mathrm{a}}$ & $22 / 03 / 2006$ \\
\cline { 2 - 3 } & $6^{\mathrm{a}}$ & $22 / 03 / 2006$ \\
\hline
\end{tabular}




\begin{tabular}{|c|c|c|}
\hline & $32^{\mathrm{a}}$ & $07 / 06 / 2006$ \\
\hline & $37^{\mathrm{a}}$ & $14 / 06 / 2006$ \\
\hline & $46^{\mathrm{a}}$ & $06 / 07 / 2006$ \\
\hline & $69^{\mathrm{a}}$ & $05 / 09 / 2006$ \\
\hline & $75^{\mathrm{a}}$ & $13 / 09 / 2006$ \\
\hline & $78^{\mathrm{a}}$ & $03 / 10 / 2006$ \\
\hline & $79^{\mathrm{a}}$ & $04 / 10 / 2006$ \\
\hline & $91^{\mathrm{a}}$ & $31 / 10 / 2006$ \\
\hline & $100^{\mathrm{a}}$ & $21 / 11 / 2006$ \\
\hline & $101^{\mathrm{a}}$ & $22 / 11 / 2006$ \\
\hline & $105^{\mathrm{a}}$ & $07 / 12 / 2006$ \\
\hline & $107^{\mathrm{a}}$ & $14 / 12 / 2006$ \\
\hline & $122^{\mathrm{a}}$ & $18 / 01 / 2007$ \\
\hline $355^{\mathrm{a}}$ & $6^{\mathrm{a}}$ & $21 / 03 / 2007$ \\
\hline & $25^{\mathrm{a}}$ & $10 / 05 / 2007$ \\
\hline & $27^{\mathrm{a}}$ & $15 / 05 / 2007$ \\
\hline & $30^{\mathrm{a}}$ & $05 / 06 / 2007$ \\
\hline & $31^{\mathrm{a}}$ & $06 / 06 / 2007$ \\
\hline & $41^{\mathrm{a}}$ & $20 / 06 / 2007$ \\
\hline & $66^{\mathrm{a}}$ & $14 / 08 / 2007$ \\
\hline
\end{tabular}

Asimismo, algunas de las temáticas más productivas para nuestro análisis desarrolladas en las 28 sesiones que conforman la muestra de discurso analizado fueron las siguientes: la legislación del aborto terapéutico, la distribución en consultorios y la discusión sobre el carácter abortivo de la "píldora del día después" (anticonceptivo de emergencia), la malversación de recursos en el Instituto Nacional de Deportes de Chile (Chiledeportes), los problemas en la asignación del crédito para educación superior con aval del Estado, la Ley Orgánica Constitucional de Enseñanza (LOCE), los malos resultados obtenidos a nivel nacional en la prueba del Sistema de Medición de la Calidad de la Educación (SIMCE), las demandas de los deudores habitacionales (condonación de la deuda) y la situación crítica ocasionada por el nuevo sistema de transporte público del Área Metropolitana de Santiago (Transantiago), entre otros temas públicos de la contingencia nacional.

\section{PRESENTACIÓN Y ANÁLISIS DE LOS RESULTADOS}

\subsection{Estrategias de descortesía en el discurso parlamentario chileno}

En el análisis del corpus de enunciados que manifestaban descortesía hacia el interlocutor relevado en la muestra del presente estudio identificamos las siguientes estrategias principales: atacar la imagen pública del oponente y resguardar la propia imagen pública. Asimismo, la primera de estas estrategias puede desglosarse en las siguientes tácticas secundarias o subestrategias: desacreditar, ridiculizar y amedrentar. Tal como se señaló en 2.3, los actos discursivos "humillar" e "ignorar" no fueron verificados en nuestros materiales, ya que la situación de interacción que caracteriza al debate entre parlamentarios no es de tipo asimétrico. 


\section{Abelardo San Martín, Silvana Guerrero}

En el Gráfico 1 se señalan las frecuencias de ocurrencias de los enunciados descorteses que pueden adscribirse a las estrategias y tácticas de descortesía de los parlamentarios que intervinieron en las sesiones que conforman la muestra del estudio.

GRÁFICO 1: FRECUENCIA ESTRATEGIAS DE DESCORTESÍA EMPLEADAS EN EL CORPUS

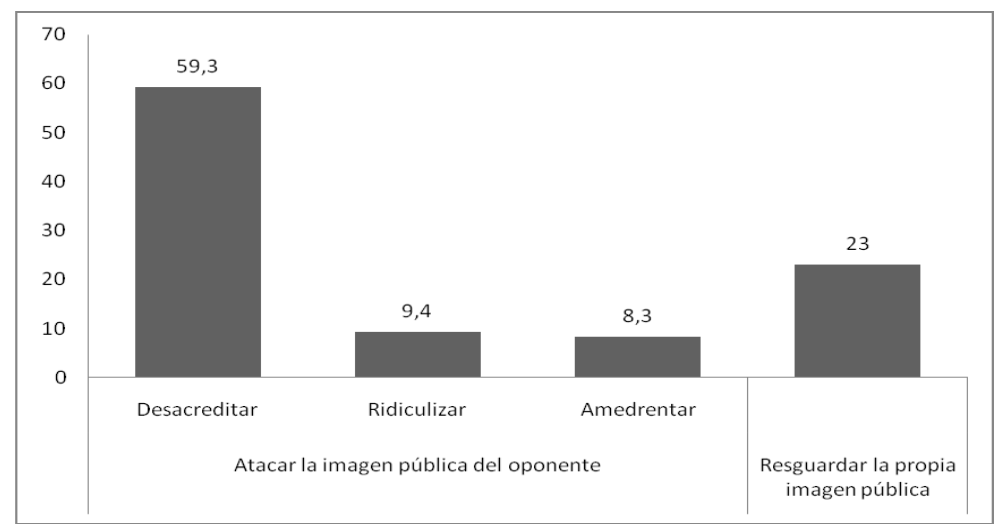

Como se desprende del Gráfico 1, se registró una mayor cantidad de ataques a la imagen pública del oponente (773/1001) en comparación con los casos en los que el objetivo era resguardar la propia imagen pública (228/1001). Asimismo, las desacreditaciones que atacan la imagen del oponente son las que registran el mayor porcentaje con un 59,3\% (594/1001). Le sigue, en orden descendente, el resguardo de la propia imagen pública con el 23\% (228/1001) del total de la muestra. A mayor distancia están las ridiculizaciones mediante las cuales se ataca al adversario con el 9,4\% (95/1001) y, finalmente, los amedrentamientos que registran apenas el 8,3\% (84/1001) de casos del total de la muestra. A continuación se definen e ilustran las estrategias y tácticas antes mencionadas.

\subsubsection{Atacar la imagen pública del oponente}

Para el cumplimiento de esta estrategia de expresión de descortesía se desarrollarán subestrategias o tácticas verbales en las que se presenta una imagen negativa del oponente para invalidar su imagen positiva. El acto descortés se llevó a cabo mediante la violencia verbal regulada, pues se pretendió desautorizar al adversario, poniendo especial énfasis en la presentación positiva de nosotros/nuestro en contraste con la imagen negativa de ellos/su. Dicho ataque puede abatir la imagen pública del oponente haciendo alusión implícita o explícita a nombres, instituciones o partidos políticos; de este modo, se deslegitima a un miembro o a un partido, estableciendo claras diferencias entre las bancadas políticas. Respecto de lo que es cortés o descortés, Blas Arroyo (2001) señala: 
La decisión final sobre el carácter cortés o descortés de un mensaje no dependería en última instancia de su capacidad para atacar la imagen del interlocutor, sino del grado de cumplimiento de los derechos y obligaciones establecidos en ese "contrato conversacional". Si se cumple con éstos, estaríamos ante enunciados corteses, mientras que si se vulneran, nos enfrentaríamos a enunciados descorteses" (Blas Arroyo, 2001:11).

En general, en los ataques a la imagen pública del oponente se emplea la falacia Ad hominem, esto es, de acuerdo con Weston (2001), se ataca a la persona de la autoridad alegada en lugar de atacar sus cualificaciones (127).

4.1.1.1. Desacreditar: a través de esta táctica o subestrategia se busca resaltar, por medio de actos directos o indirectos, los aspectos o rasgos negativos del oponente vinculados con su capacidad intelectual y de liderazgo, responsabilidad, calidad personal e integridad moral. Se degrada y rebaja al adversario mediante este procedimiento. En lo que sigue, se presentan y comentan los ejemplos que ilustran el empleo de esta táctica de descortesía. ${ }^{6}$ Por una parte, en los ejemplos 1,2 y 3 se alude a la incompetencia de los miembros de la colectividad política opuesta. Mientras que en 1 y 2 se formula un ataque personal, y en 3 se expresa descortesía hacia la colectividad opositora en su conjunto:

1. Este año, con la Diputada Marcela Cubillos, oficiamos a la Ministra de Salud para que nos informara cuántas píldoras se repartieron. ¿Saben qué contesto? Contestó que no sabía, que no tenía esa información. O sea, han pasado cuatro años, desde 2002 a 2006, pero el Ministerio de Salud todavía no tiene información de cuántas píldoras se han entregado (Forni, 13 de septiembre de 2006).

2. Un Ministro del Interior debe tener los atributos de capacidad, autoridad y responsabilidad. Hoy, nada de eso he visto en usted. Ni capacidad, ni responsabilidad, ni autoridad (Álvarez, 14 de agosto 2007).

3. Esa es una demostración de por qué la Concertación sigue gobernando y la Oposición no lo ha podido lograr. La Oposición no gobierna, porque no tiene nada que proponer al país (Súnico, 21 de marzo de 2007).

${ }^{6}$ Para facilitar la comprensión de los fenómenos analizados en esta sección se utilizarán las siguientes convenciones en la presentación de los ejemplos:

- Se transcribirá cada ejemplo en forma de cita incluyendo la cantidad de contexto necesaria para su comprensión.

- Al final de cada cita se pondrá, entre paréntesis, el apellido del diputado(a) o ministro que la emitió, indicándose, además, la fecha de la intervención para su correcta ubicación en la descripción de las sesiones analizadas.

- En cada una de las categorías de análisis, se enumerarán los ejemplos con el propósito de facilitar la identificación del fenómeno. 


\section{Abelardo San Martín, Silvana Guerrero}

Por otro lado, en los ejemplos 4, 5, 6 y 7 se apela a la inconsecuencia de los miembros de la bancada contraria:

4. ¡Por favor! ¡Aquí no estamos hablando de convicciones, sino de principios, del derecho a la vida! Y si no soy capaz de defender un principio, es mejor que renuncie, pues no me puedo escudar en las convicciones para aprobar cualquier cosa (Kast, 13 de septiembre de 2006).

5. También quiero valorar el hecho de que en este debate, la Iglesia Católica y muchas iglesias evangélicas, al igual como lo hicieron en la dictadura militar, hoy también defienden los derechos humanos, a pesar de los insultos e improperios de parte de los que hoy son gobierno. Lamento que los mismos que ayer se escudaron en la Iglesia para defender sus derechos humanos — quizá, gracias a ella muchos de ellos están vivos- hoy denosten a la Iglesia que ha sacado su voz valiente para defender a los que no tienen voz ni a los que no pueden defenderse (Sabag, 13 de septiembre de 2006).

6. En el ámbito de la transparencia, debo recordar que la primera acción que realizó la Comisión, después de que los diputados de la Alianza se retiraron de ella, fue invitarlos, en todos los tonos, a reintegrarse. No es posible funcionar así, porque se rompe el fair play; no puede ser que cuando nos conviene, integramos la Comisión, y cuando no, nos retiramos (Accorsi, 10 de mayo de 2007).

7. Quiero expresar enfáticamente que este Gobierno es hipócrita y actúa con doble estándar, porque prometió ser un gobierno ciudadano, para lo cual ha dicho hasta el cansancio que dará prioridad a la consulta, a la medida ciudadana, a la participación; pero hoy pasa a llevar a los padres de Chile como si no existieran y no tuvieran responsabilidad alguna sobre la vida de sus hijos (Cristi, 13 de septiembre de 2006).

En 4 se emplea la partícula por favor, la que se asocia comúnmente al acto de habla "solicitud cortés", como un intensificador que legitima la postura del hablante y deslegitima la del adversario; de igual modo, a dicho enunciado también podría asignársele un significado pragmático de "protesta". Este empleo de mitigadores que atenúan la agresividad de enunciados descorteses en el discurso político es también identificado por Blas Arroyo en diferentes trabajos $(1998,2003)$. En 6, por su parte, se recurre a la metáfora "la política es un deporte", ya que se emplea la expresión fair play "juego limpio", a fin de denostar la conducta del bando opositor. Cabe destacar, además, que la diferenciación entre el ataque dirigido a la inconsecuencia o el ataque dirigido a la incompetencia del adversario han sido, igualmente, reconocidos por Blas Arroyo (2001) entre los recursos de descortesía política.

Por último en 8,9 y 10 se acusa directamente a los miembros de la colectividad contraria de actos de corrupción:

8. Quiero terminar mis palabras señalando que para hablar de corrupción no hay que tener tejado de vidrio, y muchos de los que están al frente fueron cómplices del régimen más ladrón de la historia del país. Es cosa de ver las cuentas 
millonarias que el señor Pinochet tiene en el extranjero (Espinoza, 10 de enero de 2006).

9. La Cámara ha sido, por el afán de eximir de responsabilidades a los partidarios de la Concertación, cómplice de todos y cada uno de los robos y delitos que se han cometido en Chiledeportes. Esta complicidad es antigua y avergüenza (Vargas, 10 de mayo de 2007).

10. Pero no es sólo eso. No les bastó con asesinar, con ejecutar, con hacer desaparecer personas. Pusieron más de un cadáver en una misma tumba, y Augusto Pinochet dijo después que era por economía (Allende, 14 de diciembre de 2006).

En 8 y en 10, incluso, se apela a la identificación de la centro-derecha política chilena con la Dictadura Militar, lo que constituye una estrategia de deslegitimación recurrente por parte de la Concertación, el bloque político de la centro-izquierda chilena. Mediante esta identificación, en 8 se inhabilita la capacidad de crítica al adversario debido a las faltas cometidas en el pasado, recurso que también ha sido identificado por Blas Arroyo (2001) para el debate político español.

4.1.1.2. Ridiculizar: con esta subcategoría se pretende convertir directa o indirectamente al oponente en objeto de burla, haciendo que los demás se mofen de él, sea por sus cualidades o por sus acciones, por lo tanto, se lo rebaja tanto en el ámbito personal como profesional.

En términos generales, los casos adscritos a esta categoría plantean comparaciones o analogías con situaciones ridículas:

1. Cualquier persona que ve lo que está ocurriendo en esta Sala a través del canal de televisión y escuchara solamente a los colegas de la Concertación podría pensar que estamos en el país de las maravillas (Kast, 22 de marzo de 2006).

2. Usted es muy simpática para hacer preguntas. Hace una contrarrespuesta y después me hace una pregunta distinta. Imagino que si hubiese sido hombre le hubiera preguntado si jugaba al fútbol, porque realmente lo hace muy bien (Zilic, 14 de junio de 2006).

3. Entonces, ¿todas las investigaciones de las fiscalías y el Ministerio Público serían un invento de la prensa? ¿Acaso la prensa hizo que la Directora Depassier falsificara su currículo? ¿Las denuncias de los funcionarios de Chiledeportes son una creación de la imaginación de un periodista? ¿Tal vez las señoras veteranas, con problemas auditivos y con más de 80 años, son efectivamente instructoras de lucha libre? Le pido a la Cámara, particularmente a la mayoría de la Concertación, que no siga haciendo el ridículo en este asunto (Vargas, 10 de mayo de 2007).

4. Por otra parte, habla de equidad cuando le conviene. Ha dicho que esa pastilla hay que entregarla gratuitamente a las menores de los sectores más modestos, porque las de los sectores más acomodados tienen dinero para comprarla. Es decir, si quienes conforman el sector más acomodado 


\section{Abelardo San Martín, Silvana Guerrero}

compran cocaína el día de mañana, ¿significa que habría que regalar ese estupefaciente en las poblaciones? Eso no puede ser. Es la comparación más absurda que he escuchado (Cristi, 13 de septiembre de 2006).

5. Hay muchos otros circos a los que se puede ir a actuar de manera barata, como se ha hecho en algunos casos. Aquí debemos ser más serios y entregar propuestas para solucionar definitivamente el problema del Transantiago (Pérez, 21 de marzo de 2007).

En 1 se recurre a un intertexto muy conocido mediante el cual se compara irónicamente la discusión o el debate político de la Cámara con la obra de Lewis Carroll Alicia en el país de las maravillas. Por su parte, en 2 nuevamente se recurre a la metáfora "la política es un deporte", a fin de denostar mediante un sarcasmo la forma de interrogar de una diputada opositora. En 3, 4 y 5, por otro lado, el empleo de la analogía para ridiculizar al adversario es aún más evidente. En 3 se emplean preguntas retóricas que aluden a diversas situaciones ridículas con el propósito de resaltar la falta de argumentos sólidos en la defensa por actos de corrupción atribuidos a funcionarios públicos de la Concertación. En el ejemplo 4 se intenta apelar a la reducción al absurdo; no obstante, al no ser comparable un anticonceptivo con un estupefaciente, el recurso empleado resulta falaz o aplicado de modo lógicamente inadecuado. Por último, en 5 se hace una moción de orden a la seriedad en el trabajo de los diputados plateando una analogía entre el trabajo de la Cámara y un circo pobre. La ridiculización del adversario como estrategia de descortesía política también es identificada por Blas Arroyo (2001) y Bolívar (2005) en el discurso político español y venezolano respectivamente.

\subsubsection{Amedrentar:}

En este caso, la meta u objetivo político es atemorizar al oponente, sea implícita o explícitamente. De este modo, se lo debilita, pues se cierne una constante amenaza a su capacidad intelectual y moral. En nuestro corpus la frecuencia de este procedimiento es ostensiblemente menor; no obstante, destacamos los siguientes ejemplos:

1. Entiendo la desesperación y la histeria de la Izquierda y de la Concertación, porque hemos demostrado que casi la mitad de los chilenos seguimos valorando una obra gruesa, que se va a multiplicar mirando el futuro, no quedándonos en el pasado, porque le guste o no le guste a la gente de la Concertación, tengan claro que vamos a ser gobierno y vamos a limpiar a este país de la gran corrupción que hay (Moreira, 14 de diciembre de 2006).

2. Espero que hoy, o a más tardar el 21 de mayo, en el discurso en que la Presidenta de la República tendrá que dar cuenta de la marcha política y administrativa del país, proponga soluciones concretas. Si no las hay, que el pueblo y la patria se las demanden (Melero, 15 de mayo de 2007). 
Como puede apreciarse en los ejemplos anteriores, el emisor de cada enunciado formula un discurso de manera tal que su opositor se vea, a lo menos, levemente, intimidado. En 1 se presenta una amenaza de futuro cambio de Gobierno con consecuencias negativas para la coalición gobernante en el periodo analizado. En 2, por su parte, el enunciado Si no las hay, que el pueblo y la patria se las demanden corresponde a un intertexto de la toma de juramento de los ministros de gobierno en la asunción al mando de los presidentes de Chile, el que, precisamente, enfatiza la gran responsabilidad de los mismos en la conducción política del país.

Cabe destacar que, como era de suponerse, el amedrentamiento tiene una menor incidencia entre las tácticas de descortesía en el discurso parlamentario, debido a que el debate en la Cámara corresponde a una situación de interacción simétrica entre pares, por lo que el acto de amenaza se ve sistemáticamente aminorado (ver más arriba p. 8), a no ser que se violenten derechamente las normas de buena conducta en el debate parlamentario. Nuevamente, al igual que los recursos anteriores, el amedrentamiento ha sido identificado entre los recursos de descortesía política por Blas Arroyo (2001) y Bolívar (2005).

\subsubsection{Resguardar la propia imagen pública}

Este recurso de descortesía se refiere al enaltecimiento de las acciones, los logros y los rasgos positivos del conglomerado político en el que milita cada parlamentario que interviene en la muestra analizada, en particular. Asimismo, también puede incluir la caracterización positiva de rasgos o cualidades personales propias del emisor o de alguno de sus correligionarios. En ambos casos, el objetivo político es opacar por contraste a los integrantes del bando opositor, individualmente, o a la bancada opuesta, en su conjunto, como conglomerado político. Cabe destacar que se trata de una estrategia que forma parte del fenómeno de la descortesía solo en el sentido en que se busca un enaltecimiento de la propia imagen pública en desmedro o como parte de una crítica al comportamiento verbal y no verbal del bando opositor. En los ejemplos siguientes, como puede apreciarse, se configura discursivamente una imagen pública propia caracterizada por la credibilidad, el compromiso y la responsabilidad en el cumplimiento de las obligaciones y deberes políticos, como parte de una réplica a las críticas de parlamentarios de la bancada opositora. Asimismo, como contrapartida, se atribuyen rasgos negativos de falta de probidad y negligencia en el cumplimiento de dichas obligaciones a los parlamentarios del bando contrario:

1. Pues bien, por su intermedio, señor Presidente, solicito le haga ver al diputado Burgos y a sus compañeros de partido que se equivoca y que falta a la verdad. No fui a ningún safari, asistí a todas las sesiones, voté en nombre de Chile para que nunca más una mujer sea golpeada ni siquiera por parlamentarios de ningún partido. No fui a turistear como, pareciera, a él le gustaría. Lo lamento (Henríquez- Ominami, 6 de julio de 2006). 


\section{Abelardo San Martín, Silvana Guerrero}

2. Señor Presidente, cuando uno dice la mitad de la verdad, ésta pasa a ser mentira. La UDI sí estuvo interesada en que la Comisión funcionara. Les recuerdo a los honorables colegas, por su intermedio, señor Presidente, que, cuando nos reunimos en Concepción y en Los Ángeles, la UDI dio el quórum necesario a la Comisión para sesionar. Precisamente, fuimos nosotros quienes le dimos la posibilidad de sesionar en ambas ocasiones. Teníamos interés y siempre lo mantuvimos (Lobos, 18 de enero de 2007).

En general, tanto en 1 como en 2 se acusa a miembros de la bancada opositora de faltar a la verdad. Particularmente, en 2 se le atribuye al contrario el mentir a través de "medias verdades", táctica que también ha sido identificada en el discurso político español por Blas Arroyo (2001). Asimismo, en 1 la secuencia final Lo lamento consiste en otro caso de atenuación de la agresividad del enunciado del mismo tipo que el caso del empleo de por favor comentado anteriormente (ver 4.1.1.1).

Por último, en los ejemplos 3, 4 y 5 se realiza una autocaracterización o un perfil de sí mismo en términos altamente positivos, pero con el fin de denostar la conducta irresponsable, falaz y demagógica de los miembros de la bancada opuesta.

3. Quiero terminar mi intervención señalando, tanto en nombre propio como en el de Renovación Nacional, que tenemos la mejor disposición para colaborar en la lucha contra la delincuencia sin demagogia, sin mentiras y sin engaños (Errázuriz, 31 de agosto de 2005).

4. Nosotros entendemos la responsabilidad política como un ejercicio diario. Lo decimos no sólo en este hemiciclo, sino también en la televisión. Lo hemos hecho y lo vamos a seguir haciendo cotidianamente. Si algún parlamentario de la UDI tiene alguna duda, yo respondo (Ex - Ministro de Transportes Sergio Espejo, 21 de marzo de 2007).

5. No es mi costumbre responder ni siquiera cuando soy atacado; claro que coloco la otra mejilla, porque sé que lo que hago, lo trato de hacer bien. No soy perfecto, es imposible. No existe la verdad absoluta ni la perfección absoluta; pero trato de cumplir con mi deber. Prueba de ello es que en los casi once años que llevo en la Cámara de Diputados, sólo una vez estuve aquejado de una enfermedad que me impidió asistir durante seis sesiones. Nunca más he fallado; ésa es responsabilidad con la ciudadanía (Jaramillo, 10 de mayo de 2007).

4.2. Distribución de estrategias de descortesía por conglomerado político

Por lo que refiere al empleo de las estrategias de descortesía por parte de las dos grandes coaliciones políticas cuyos representantes intervinieron en la muestra seleccionada, a continuación se presentan en el Gráfico 2, los resultados globales de nuestra pesquisa por conglomerado político. 
GRÁFICO 2: FRECUENCIA DE ESTRATEGIAS DE DESCORTESÍA POR CONGLOMERADO POLÍTICO

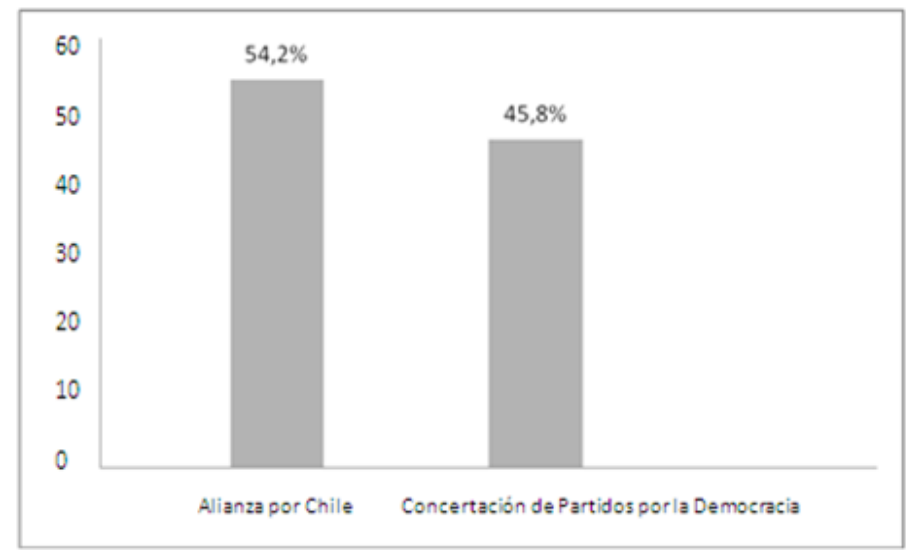

Como puede apreciarse, los diputados pertenecientes a la Alianza por Chile, conglomerado político de la centro-derecha chilena, emplearon estrategias de descortesía en 543/1001 ocasiones, lo que equivale al 54,2\%. Por su parte, los parlamentarios de la Concertación de Partidos por la Democracia, coalición de centro-izquierda que gobernó el país entre 1990 a 2010, recurren a estrategias de descortesía en 458/1001 casos lo que representa el 45,8\%. Si bien se trata de una leve diferencia desde el punto de vista estadístico, puede interpretarse el mayor empleo de estrategias de descortesía debido al papel opositor desempeñado por los miembros de la Alianza por Chile en el periodo analizado en este estudio; no obstante, los diputados concertacionistas, como ya se señaló, recurren en gran proporción también a estrategias de descortesía como tácticas de defensa de los ataques de los diputados aliancistas.

\section{CONCLUSIONES}

Los resultados más significativos del presente estudio pueden sintetizarse como sigue:

1. A partir del análisis realizado a las transcripciones de 28 sesiones de la Cámara de Diputados de Chile realizadas entre 2005 y 2007 que conformaron la muestra de nuestra investigación, relevamos 1001 casos de empleo de estrategias de descortesía verbal. Las estrategias de descortesía en el discurso parlamentario chileno pueden clasificarse en dos grandes categorías: 1) atacar la imagen pública del oponente (773 ocurrencias) lo que equivale al $77 \%$ y 2 ) resguardar la propia imagen pública (228 casos) que corresponden al 23\%. La primera de dichas estrategias, a su vez, puede subclasificarse en las siguientes tácticas: desacreditar (594 ocurrencias) lo que equivale al 59,3\%; ridiculizar (95 casos) que corresponden al 9,4\% y, finalmente, amedrentar (84 ocurrencias) equivalentes al 


\section{Abelardo San Martín, Silvana Guerrero}

$8,3 \%$. Por otra parte, la distribución estadística en el empleo de estrategias de descortesía en la muestra analizada es levemente superior para la Alianza por Chile (543 casos con el 54,2\%), conglomerado político que cumplió el papel opositor en el periodo analizado por sobre la Concertación de Partidos por la Democracia (458 ocurrencias correspondientes al 45,8\%), que gobernó en país en el mismo periodo.

2. En nuestro trabajo hemos podido comprobar que los enunciados descorteses constituyen una característica del debate político cara a cara, puesto que en una gran parte de las interacciones de la Cámara de Diputados se pretendió alterar el equilibrio interpersonal desafiando normas y violando el "contrato conversacional" que debería caracterizar el comportamiento verbal de los diputados. De este modo, el debate político constituye un escenario de confrontación entre dos polos opuestos en cuyos intercambios el desafío a las normas de cortesía es constante, de modo que la interacción transita continuamente entre recursos como el ataque a la imagen del oponente y el resguardo de la imagen propia. Esta percepción del discurso político como un verdadero campo de batalla en la que el lenguaje es considerado una verdadera arma mediante la cual se pretende "destruir" al adversario y, de este modo, suscribir la adhesión del potencial electorado es también desarrollada por Blas Arroyo en diferentes trabajos (1998, 2000, 2001 y 2003).

3. Por último, respecto a la incidencia en la utilización de recursos descorteses que puede tener la pertenencia a una $\mathrm{u}$ otra bancada política, debemos señalar que nuestra pesquisa permitió corroborar que, tanto desde el punto de vista cuantitativo como cualitativo, el empleo de las estrategias de descortesía se ve solo levente influenciado por dicho factor. En este sentido, podríamos destacar que el mayor empleo de estrategias de descortesía se manifestó en los parlamentarios de la Cámara de Diputados pertenecientes a la Alianza por Chile, lo que podría asociarse con el objetivo de generar polémicas, descalificar y desacreditar, en el mayor grado posible, a los miembros de la coalición que estaba a cargo del país durante el período legislativo considerado en este análisis (2005-2007), esto es, la Concertación de Partidos por la Democracia, que gobernó el país desde 1990 hasta 2010. Los parlamentarios y funcionarios de gobierno de este conglomerado, no obstante, también recurren en gran proporción a las estrategias y tácticas de descortesía con el propósito de defender su propia imagen política como coalición gobernante. En este sentido, una de las principales proyecciones de este estudio sería investigar las estrategias de descortesía en la situación de gobierno actual, esto es, cuando la Alianza por Chile es la coalición gobernante. De este modo, el Análisis del discurso, en general, y los estudios de (des)cortesía, en particular, pueden contribuir significativamente al ámbito de la ciencia política, ya que proporcionan herramientas analíticas que permiten objetivar las peculiaridades del comportamiento verbal de los actores políticos. 


\section{BIBLIOGRAFÍA}

Bernal, María. Categorización sociopragmática de la cortesía y de la descortesía. un estudio de la conversación coloquial española. Departament of Spanish, Portuguese and Latin American Studies, Stockholm University. (Disponible en: http://edice.org/7-descargas/), 2007.

Blas Arroyo, José Luis. "Perdóneme que se lo diga, pero vuelve usted a faltar a la verdad, señor González: form and function of politics verbal behaviour in face to face Spanish political debates". Discourse \& Society Vol. 14, No 4. 2003:395- 423 .

------- "No digas chorradas. La descortesía en el debate político cara a cara. Una aproximación variacionista". Oralia 4. 2001:9-45.

------ "Mire usted Sr. González. Personal Deixis in Spanish Political- Electoral Debate", Journal of Pragmatics 32, 1. 2000:1-27.

"Pero no me interrumpa usted, haga el favor. Las interrupciones en el debate político-electoral", Mediterranean Language Review 10. 1998:54-88.

Bolívar, Adriana. "La descortesía en la dinámica social y política", en Jorge Murillo (Ed.) Actas del II Coloquio del Programa EDICE. Costa Rica: Universidad de Costa Rica, 2005:137- 164.

------ "Violencia verbal, violencia física y polarización en el diálogo político venezolano", en Molero, L. y Franco (Eds.) El discurso político desde las humanidades y las ciencias sociales. Caracas: Fonacit, 2002:125-136.

------ (Comp.). "Estudios en el análisis crítico del Discurso". Cuadernos de postgrado 14 (1996). Caracas: Consejo de Desarrollo Científico y Humanístico.

"The analysis of political discourse, with particular reference to the Venezuelan political dialogue", English for Specific Purposes 11 (2). 1992:159-175.

Bolívar, Adriana; Frances de Erlich e Irma Chumaceiro. "Divergencia, confrontación y atenuación en el diálogo político", Revista Iberoamericana de Discurso y Sociedad 4, 3. 2003:121-151.

Brown, Penélope y Stephen Levinson. Politeness. Some Universals in Language Use. Cambridge: Cambridge University Press, 1987.

Chilton, Paul y Christina, Schäffner. Politics as Text and Talk. Analytic approaches to political discourse. Amsterdan/Philadelphia: John Benjamins Publishing Company, 2002.

------- "Discurso y política", en van Dijk (ed.) El discurso como interacción social. Estudios sobre el discurso II. Una introducción multidisciplinaria. Barcelona: Gedisa, 1999:297-329.

Culpeper, Jonathan. "Towards an anatomy of impoliteness. Journal of Pragmatics 25. 1996:349-367. 


\section{Abelardo San Martín, Silvana Guerrero}

Fernández, Francisco. Estrategas del diálogo. La interacción comunicativa en el discurso político-electoral, Granada: Método Ediciones, 2000.

Flores, María Eugenia y José María Infante. "Polifonía y (des)cortesía en el debate político". En Orletti, F. y L. Mariottini (Eds.). Descortesía en español. Espacios teóricos y metodológicos para su estudio. Publicado por la Università Degli Studi Roma Tre y el Programa EDICE, 2010:137-156.

Fraser, Bruce. "Perspectivas on Politiness". Journal of Pragmatics 14. 1990:219236.

Fraser, Bruce y William Nolen. "The association of deference with linguistic form", International Journal of the Sociology of Language, 27. 1981:93-107.

Goffman, Erwin. La presentación de la persona en la vida cotidiana. Buenos Aires: Amorrortu, 1971.

Haverkate, Henk. La cortesía verbal. Estudio pragmalingüístico. Madrid: Gredos, 1994.

Kienpointner, Manfred. "Varieties of Rudeness: Types and Functions of Impolite Utterances". Functions of Language 4, 2. 1997:251-287.

Lakoff, George y Mark Johnson. Metáforas de la vida cotidiana, Madrid: Cátedra, 1995.

Lakoff, Robin. "The limits of politiness". Multilingua 8. 1973:101-129.

Leech, George. Principles of Pragmatics. Londres: Longman, 1983.

Martin Rojo, Luisa. "Enfrentamiento y consenso en los debates parlamentarios sobre la política de inmigración en España", Oralia 3. 2000:113-148.

Montero, Maritza. "La retórica amenzante y crisis de la gobernabilidad en Venezuela", Revista Iberoamericana de Discurso y Sociedad 4, 3. 2003:37-56.

Shiro, Martha y Nancy Núñez. "La credibilidad y la confiabilidad en el discurso político venezolano", Revista Iberoamericana de Discurso y Sociedad 4, 3. 2003:99-120.

Tannen, Deborah. La cultura de la polémica. Del enfrentamiento al diálogo. Barcelona: Paidós, 1999.

------ "The Triumph of the Yell", Georgetown University Round Table on Languages and Linguistics: Educational linguistics, crosscultural communication, and global interdependence, 1994:23-25.

Van Dijk, Teun. Ideología y discurso. Barcelona: Ariel, 2003.

------- El discurso como interacción social. Estudios sobre el discurso II. Una introducción multidisciplinaria. Barcelona: Gedisa, 1999.

Weston, Anthony. Las claves de la argumentación. Barcelona: Ariel, 2001.

Wodak, Ruth y Michael Meyer. Métodos de análisis crítico del discurso. Barcelona: Gedisa, 2003.

Wodak, Ruth. "El enfoque histórico del discurso", en Wodak, R. y M. Meyer (Eds.), 2003:101-142. 